\title{
Görüntü İşleme Teknikleriyle Yüz Algılama Sistemi Geliştirme
}

\author{
Ayşe ELDEM ${ }^{1 *}$, Hüseyin ELDEM ${ }^{2}$, Abdurrahman PALALI $^{2}$ \\ ${ }^{1}$ Karamanoğlu Mehmetbey Üniversitesi, Bilgisayar Mühendisliği Bölümü, Karaman \\ ${ }^{2}$ Karamanoğlu Mehmetbey Üniversitesi, Bilgisayar Teknolojileri Bölümü, Karaman
}

\begin{abstract}
Özet
Bilgisayar bilimlerindeki önemli çalıșma konularından biri de görüntü işlemedir. Bir görüntüden faydalı bir bilgi çıkarılarak yorumlanması gerektiğinde görüntü işleme tekniklerinden faydalanılmaktadır. İşlenecek görüntü, kameralar, optik tarayıcılar ve fotoğraf makineleri yardımıyla elde edilebilir. $\mathrm{Bu}$ dijital görüntülerin sayısallaştırılmasıyla üzerinde farklı işlemler uygulanarak anlamlı yorumlanabilir sonuçlar elde edilebilir. Tıp, Askeri, Endüstriyel ve Coğrafi Sistemler gibi birçok alanda kullanılan görüntü işleme teknikleri, güvenlik sistemleri alanında da yaygın olarak kullanılmaktadır. Parmak izi, iris ve yüz tanıma gibi uygulamalar güvenlik alanında görüntü işleme teknikleri kullanılarak yapılabilmektedir. Tarayıcı, kamera ya da fotoğraf makinesi üzerinden alınan görüntülerin yorumlanabilmesi için belirli ön işlemlerden geçirilmesi gerekmektedir. Bu konuda yazılımsal olarak programlama dilleriyle geliştirilmiş birçok kütüphane bulunmaktadır. Açık kaynak kodlu bir kütüphane olan OpenCV (Open Source Computer Vision Library) bu çalışmada tercih edilen görüntü işleme kütüphanelerinden biridir. Geliştirilen uygulamada OpenCV' nin C\# için geliştirilmiş olan OpenCVSharp bileşeni kullanılmıştır. Kamera ile bireylerin fotoğrafları elde edilerek bireylerin yüz bölgeleri bulunmuştur. Ardından veritabanında kayitlı olan verilerle karşılaştırılarak bireyin hangi oranda kime benzediği geliştirilen program aracılığıyla gösterilmiştir. Yapılan bu çalışmada yüz tanımada \%79 oranında başarı sağlanmıştır.
\end{abstract}

Anahtar kelimeler: Görüntü İşleme, OpenCV, OpenCVSharp, Yüz Tanıma.

\section{Face Recognization System Development with Image Processing Techniques}

\begin{abstract}
One of the important study topics in computer science is image processing. When useful information needs to be interpreted by extracting from an image, image processing techniques are utilized. The image to be processed can be obtained with the help of cameras, optical scanners and photographic machines. By digitizing these digital images, different interpretations can be applied to obtain meaningful interpretable results. Image processing techniques used in many fields such as Medical, Military, Industrial and Geographical Systems and also widely used in the field of security systems. Applications such as fingerprint, iris and face recognition can be performed using image processing techniques in the field of security. To be able to interpret the images taken via scanner, camcorder or camera, certain preprocessing needs to be done. In this regard, as a software there are many libraries developed by programming languages. OpenCV (Open Source Computer Vision Library), an open source library, is one of the preferred image processing libraries for this work. The developed application uses OpenCVSharp component developed for C \# in OpenCV. By photographing the individual with the camera, facial regions of the individual were found. Then, by comparing the data stored in the database, similarity rate of the persons to the other persons is shown through the developed program. In this study, $\% 79$ of achievement succeed in face recognition.
\end{abstract}

Keywords: Image Processing, OpenCV, OpenCVSharp, Face Recognition.

*Sorumlu yazar: ayseeldem@kmu.edu.tr

Geliş Tarihi: 10/08/2017 Kabul Tarihi: 13/10/2017

Bu çalışmanın özet bölümü 2017 Imeset Uluslararası Konferası'nda 12-14 Haziran tarihinde sunulmuştur. 


\section{Giriş}

Görüntü işleme, herhangi bir aygıt aracılı̆̆ıyla alınan görüntüler üzerinde herhangi bir işlem yapabilmeyi sağlayan tekniğe verilen isimdir. Görüntü işleme; herhangi bir görüntünün netliğini artırma, görüntü üzerinde bulunan herhangi bir nesnenin elde edilebilmesi ya da nesnelerin tanımlanabilmesi gibi birçok amaçla kullanılmaktadır. Herhangi bir resmin yazılım aracılığıyla kullanılabilmesi için sayısallaştırılması gerekmektedir. Sayısallaştırma; resimde bulunan renklerin sayısal değerlerle ifade edilmesidir.

Teknolojik gelişmelerin hızlı artışı sayesinde güvenlik uygulamalarında da hızlı bir artış meydana gelmektedir. Yüz, parmak izi ve iris tanıma tabanlı birçok personel otomasyonu geliştirilmektedir. Bahsedilen uygulamalarda herhangi bir görüntü alındıktan sonra üzerinde görüntü işleme adımları uygulanarak gerekli veriler elde edilmektedir. Görüntü işlemeyle ilgili standart yöntemler olmakla birlikte bu yöntemlerin haricinde geliştirilen hazır kütüphaneler de bulunmaktadır. OpenCV, EmguCV, AForge.NET bu kütüphanelerden bazıları olup yapılan işlemlerin daha hızlı bir şekilde ve daha az komut satırıyla yapılabilmesini sağlamaktadırlar.

Bu çalışmada kamera aracılığıyla görüntüsü alınan bireylerin yüz bölgesi bulunmuştur. Daha önceden oluşturulan veri tabanındaki resimlerle karşılaştırarak elde edilen yüzün veri tabanında olup olmadığı belirlenmiş ve en yüksek oranla hangi resme benzediği bulunarak ekranda gösterilmiştir. Görüntü işleme adımlarının uygulanabilmesi ve yüz bölgesinin belirlenebilmesi için OpenCVSharp kullanılmıştır.

\section{Materyal ve Metot}

OpenCV, Intel tarafından 1999 yılında geliştirilen açık kaynak kodlu görüntü işleme kütüphanesidir [1]. $\mathrm{C}, \mathrm{C}++$, Phyton ve Java arayüzleri bulunan OpenCV, Windows, Linux, Mac OS, iOS, Android gibi farklı platformlarda çalışabilmektedir [2]. BSD (Berkeley Software Distribution) lisansı sayesinde her türlü projede ücretsiz olarak kullanılabilmektedir. OpenCV, hesaplama verimliliğini artırmak ve gerçek zamanlı uygulamalar için tasarlanmıştır [3].

OpenCV'nin birçok kullanım alanı bulunmaktadır. Bunlardan bazıları;

- Yüz, göz, ağız, burun tanıma,

- Herhangi bir nesneyi tanıma,

- Videodaki hareketleri algilama,

- Şablon ve şekil eşleştirme,

- Kamera kalibrasyonu,..

OpenCV kütüphanesi CV, MLL, HighGUI ve CXCore şeklinde isimlendirilen 4 adet ana bileşenden oluşmaktadır.

- CV bileşeni: Görüntü işleme ve yüksek seviyeli görüntü işleme algoritmalarını içerir.

- MLL bileşeni: Birçok istatistiksel sınıflandırıcı ve kümeleme aracı içeren makine öğrenme komutlarını içerir.

- HighGUI bileşeni: Video ve görüntülerin saklanması ve yüklenmesi için I/O işlemlerini ve fonksiyonlarını içerir.

- CXCore bileşeni: Temel veri yapıları ve içeriğini, resim çizme gibi bölümleri içerir.

$\mathrm{Bu}$ çalışmada gerekli işlemlerin yapılabilmesi için OpenCV'nin C\# için geliştirilmiş olan wrapperlarından olan OpenCVSharp kütüphanesi, veri tabanı olarak Access tercih edilmiştir.

\section{Bulgular ve Tartışma}

Geliştirilen uygulamada ilk olarak bireylerin resimleri kamera aracıllı̆ıyla alınmıştır. Bireylerle bilgisayar kamerasının arasındaki uzaklık $60 \mathrm{~cm}$ olarak ayarlanmıştır. Ardından her bireye bir numara verilmiş, bireyin adı soyadı ve ilgili kişinin resminin adı da verilen numara olacak şekilde veri tabanına Tablo 1'de gösterildiği gibi kaydedilmiştir. 100 kişiye ait kayıt oluşturulmuş olup resimler kaydedilirken resimlerin sadece yüz bölümü kaydedilmiştir. 
Tablo 1. Veri tabanında depolanan bilgiler

\begin{tabular}{ccc}
\hline Birey Numarası & Ad Soyad & Resim Ad1 \\
\hline 1 & Ayşe ELDEM & $1 . j p g$ \\
2 & Büşra ONAT & $2 . j p g$ \\
$\ldots$. & $\ldots$ & $\ldots$ \\
99 & Hüseyin ELDEM & $99 . j p g$ \\
100 & Abdurrahman PALALI & $100 . j p g$ \\
\hline
\end{tabular}

Veri tabanı oluşturulduktan sonra herhangi bir bireyin kamera aracılığıyla görüntüsü alınarak veri tabanında var olup olmadığı kontrol edilmektedir. Bireyin görüntü alındıktan sonra gerekli kontrolün yapılabilmesi için uygulanan işlem adımları Şekil 1'de gösterilmiştir. Şekil 2'de de geliştirilen yazılımsal arayüz gösterilmiştir.

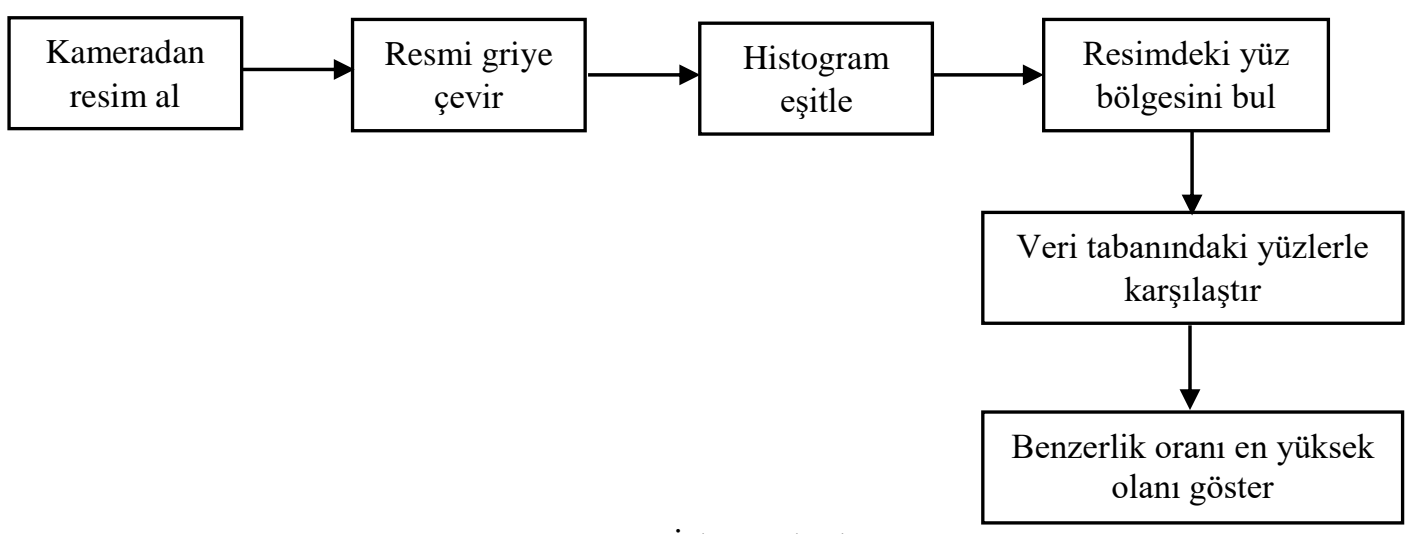

Şekil 1. İşlem Adımları

Şekil 2'de gösterilen program arayüzü kullanılarak "Kameradan Resim Al" butonu sayesinde kamera aracılığıyla resim sisteme yüklenmektedir. Bireyin görüntüsü alındıktan sonra bireyin yüz bölgesinin bulunabilmesi için "Yüzü Belirle" butonu kullanılmaktadır. Burada geliştirilen yazılımda ilk olarak renkli resim gri resme dönüştürülmektedir. Resim griye çevrilirken herhangi bir noktadaki piksel değerine ait RGB (kırmızı, yeşil, mavi) renk değerleri toplanarak 3'e bölünüp gri piksel değeri elde edilmektedir. Ardından EqualizeHist komutu ile resmin hem parlaklığı azaltılır hem de kontrastı düşürülerek resim daha belirgin hale getirilmektedir [4]. Daha sonra bireye ait yüz bölgesinin bulunabilmesi için OpenCV' nin haarcascade yapısı kullanılmıştır.

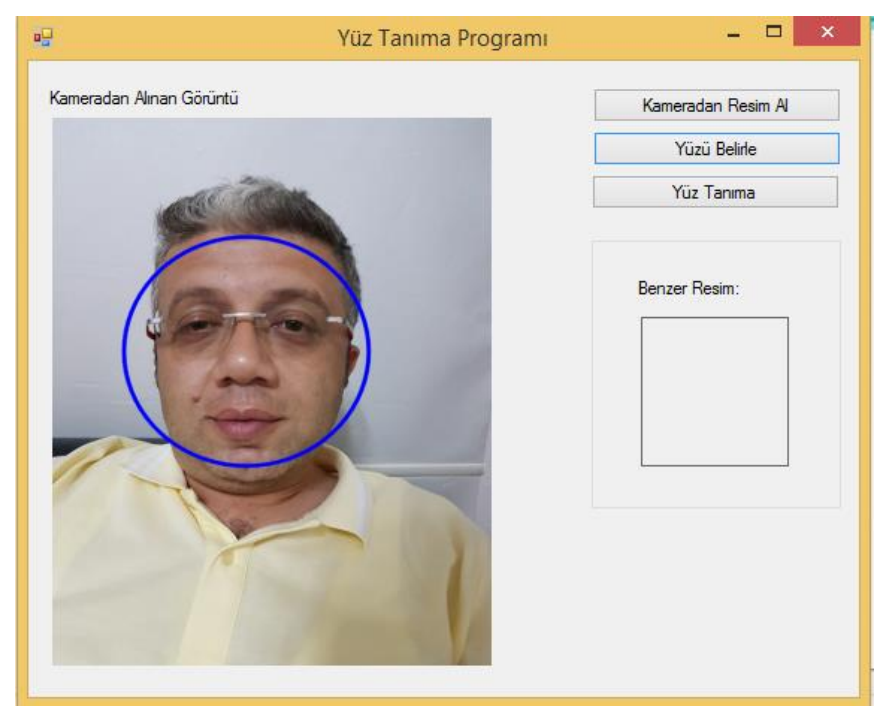

Şekil 2. Geliştirilen Yazılım 
"Yüz Tanıma" butonu ile Tablo 1'deki daha önce oluşturulan yüz verileriyle o anda alınan bireyin yüz fotoğrafi Şekil 3’te gösterildiği üzere şablon eşleştirme yöntemi kullanılarak karşılaştırılmıştır. Hata değeri en düşük olan resim en çok benzeyen resim olduğu için 100 kaydı kontrol ettikten sonra hata oranı en düşük olan resim programdaki Benzer Resim bölümüne Şekil 4'te gösterildiği gibi yüklenmektedir.

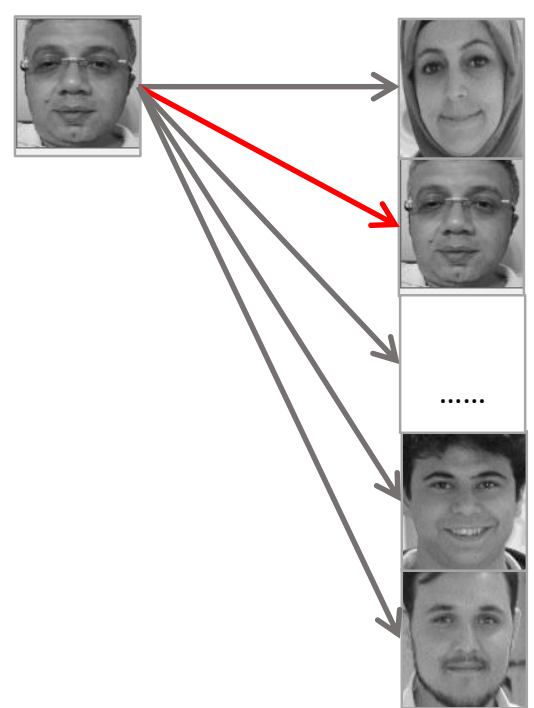

Şekil 3. Veritabanındaki Verilerle Karşılaştırma

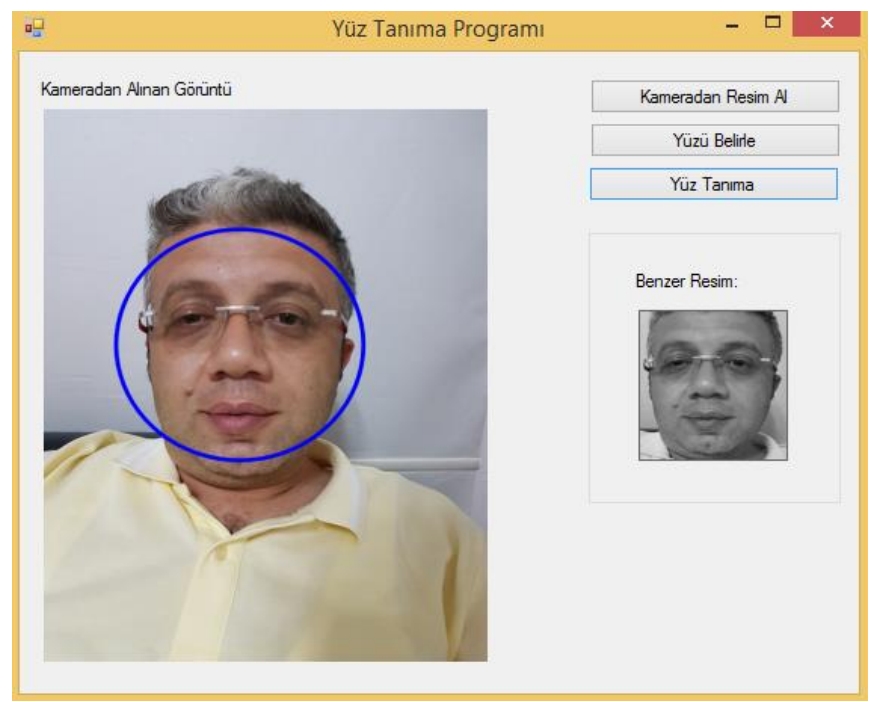

Şekil 4. Karşılaştırma Sonucu

\section{Sonuç}

$\mathrm{Bu}$ çalışmada, gelişen teknoloji ile birlikte artan güvenlik sistemleri için temel bir uygulama geliştirilmiştir. Bireylerin profil fotoğrafları kamera aracılığıyla alınarak bireylerin yüz bölgeleri OpenCV kütüphanesi kullanılarak elde edilip yüz fotoğrafları veri tabanına kaydedilmiştir. Ardından herhangi bir bireyin profil fotoğrafi alındığında o bireyin ilgili veri tabanında kayıtlı olup olmadığını bularak en çok hangi bireye benzediğini bulan bir uygulama geliştirilmiştir. Bu uygulamada yaklaşık $\% 79$ oranında bir başarı elde edilmiştir. 


\section{Kaynaklar}

1. Erişti E. 2010. Görüntü İşlemede Yeni Bir Soluk, OPENCV, Akademik Bilişim'10 - XII. Akademik Bilişim Konferansı Bildirileri, 10-12 Şubat, Muğla.

2. OpenCV. 2017. http://www.opencv.org (Erişim Tarihi: 8.7.2017).

3. Bradski G., Kaehler A. 2008. Learning OpenCV, O’Reilly Media Inc., USA .

4. Karakoç M. 2012. http://ab.org.tr/ab12/sunum/21-goruntu isleme-Karakoc.pdf (Erişim Tarihi: 08.07.2017). 